\title{
Second-Position Syncopation in European and American Vocal Music
}

\author{
DAVID TEMPERLEY[1] \\ Eastman School of Music
}

\begin{abstract}
I define a second-position syncopation as one involving a long note or accent on the second quarter of a half-note or quarter-note unit. I present a corpus analysis of second-position syncopation in 19th-century European and American vocal music. I argue that the analysis of syncopation requires consideration of other musical features besides note-onset patterns, including pitch contour, duration, and text-setting. The corpus analysis reveals that second-position syncopation was common in English, Scottish, Euro-American, and African-American vocal music, but rare in French, German, and Italian vocal music. This suggests that the prevalence of such syncopations in ragtime and later popular music was at least partly due to British influence.
\end{abstract}

Submitted 2019 June 26; accepted 2019 August 26.

KEYWORDS: rhythm, vocal music, syncopation, Scotch snap

FIGURE 1A shows a phrase from a 19th-century Scottish song. The phrase features a distinctive rhythmic gesture (inside the box): a short note on a strong quarter-note beat, followed by a longer note on the following 8th-note beat. This rhythmic pattern is of historical interest in several respects. It connects, first of all, with a characteristic rhythmic pattern of traditional English and Scottish music, known as the "Scotch snap" or simply the "snap." This term most often refers to a rhythmic pattern with a 16th-note on a quarter-note beat followed by a longer note, as in Figure 1B; but the similarity between the two patterns is readily apparent, and the term "snap" is sometimes applied to the pattern in Figure 1A as well (Hamm, 1983; van der Merwe, 1989). (We could refer to the patterns in Figures 1A and 1B as "8th-note snaps" and "16th-note snaps," respectively.) This pattern is also a characteristic feature of early 20th-century American popular musicragtime and later styles; Figure 1C shows an example from a popular song of 1906. Berlin (1980) describes such patterns as "untied syncopations," distinguishing them from "tied syncopations," in which the short note falls on a weak quarter-note beat, and the long note is tied over the following strong beat (as in Figure 1D). Several authors have informally noted the connection between the Scotch snap of traditional British music and the syncopations of 20th-century popular music (Krehbiel, 1914; Hamm, 1983; van der Merwe, 1989); part of my aim in this study is to explore this connection more systematically than has been done before.

Consider now the phrase shown in Figure 1E. This phrase features essentially the same pattern of note-onsets (in relation to the meter) as Figures 1A and 1C, yet its impact is entirely different; the effect of syncopation present in Figures 1A and 1C seems much weaker in Figure 1E, if it is present at all. This suggests that, if we are to capture the character of patterns such as Figures 1 A and 1C, considering onset patterns alone is not sufficient; other musical features must also be considered.

The current study builds on an earlier collaborative study of mine (N. Temperley \& D. Temperley, 2011). In that study, we counted Scotch snaps in several collections of 19th-century songs, finding them to be quite common in English and Scottish songs, and non-existent in German and Italian songs: not a single occurrence was found in either of the latter two repertoires. Our earlier study included only 16th-level snaps, not 8th-level ones, and defined them only in terms of onset pattern (though we required a change of syllable between the first note and the second). In the current study, I ask three questions. First, is the difference between British and continental European vocal styles still found when 8th-level snaps are included as well as 16th-level ones? Secondly, is this difference brought out more clearly when other musical features are considered besides onset pattern? Third, does the use of the snap in British music resemble that in 19thcentury American music? If so, we might conclude that its presence in ragtime and later genres is partly the 
result of British influence; if not, that would suggest a further evolution internal to American music, or perhaps the influence of other, especially African, musical traditions.

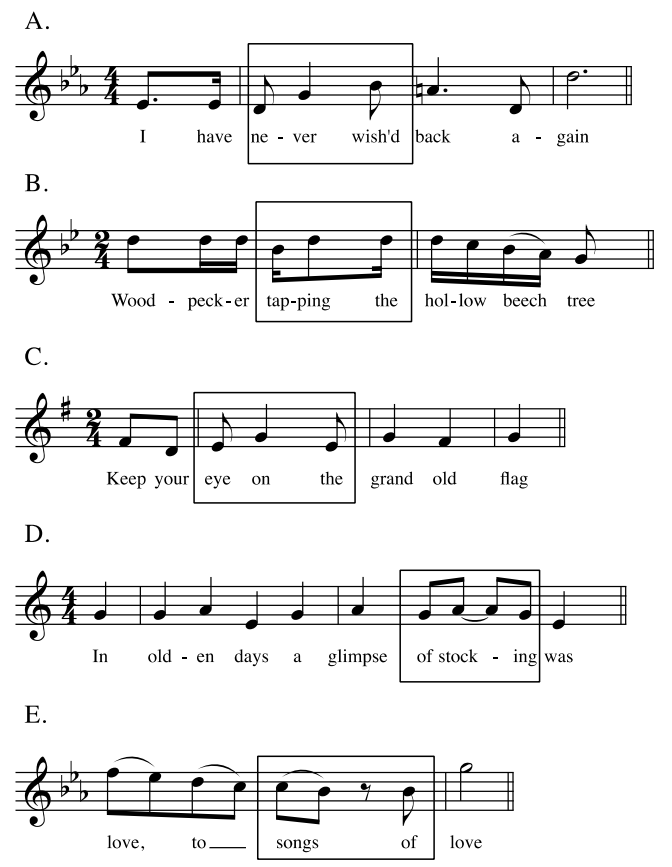

Fig. 1. (A) Dora Greenwell and Jacques Blumenthal, "Answers," mm. 25-6, in Songs of Scotland, 87; (B) Thomas Moore and Michael Kelly, "The Woodpecker," mm. 17-18, in Songs of England, 173; (C) George M. Cohan, "You're A Grand Old Flag," mm. 82-5; (D) Cole Porter, "Anything Goes," mm. 21-2; (E) Thomas Morton and Henry Bishop, "Pretty Mocking Bird," mm. 28-9, in Songs of England, 63.

Before we proceed, some additional terms are needed. While Berlin's "tied/untied" terminology is intuitive, it is not ideal; in particular, a tied syncopation does not necessarily carry a literal tie. In general, the identity of a syncopation seems to depend more on its metrical position than on its literal duration (though duration plays some role, as we will see). I propose the term "second-position syncopation" to refer to a syncopation on the second quarter of a half-note or quarter-note span (as in Figures 1A, 1B, and 1C); a "fourth-position" syncopation is one on the fourth quarter of such a span (as in Figure 1D). In this study, our main focus is on second-position syncopation, though I briefly discuss fourth-position syncopation in the final section.

\section{SYNCOPATION}

A useful starting point for our investigation is Lerdahl and Jackendoff's concept of phenomenal accent, which they define as "any event at the musical surface that gives emphasis or stress to a moment in the musical flow" (1983, p. 17). Important sources of phenomenal accent include note-onsets (a beat with a noteonset is more accented than a beat without one), long notes (sometimes known as "agogic accent"), loud notes, stressed syllables, and changes of harmony. (In this context, the "length" of a note is often defined as its "inter-onset interval" - the time interval between the note's onset and that of the following note.) Generally, phenomenal accents fall on relatively strong metrical positions; this is what conveys the meter to the listener. However, phenomenal accents may conflict with the meter to some extent-a weak beat may carry a stronger phenomenal accent than a neighboring strong beat; this is syncopation. For example, in Figure 1A, the 8th-level beat carrying the syllable "-ver" is accented (due to the fact that it is a relatively long note), more so than the stronger beats on either side: the following quarter-note-level beat carries no note-onset at all, and the previous whole-note-level beat carries a short note. We can label syncopations according to the metrical level of the accented weak beat: thus, Figures 1A, 1C, 1D, and 1E have 8th-level syncopations (though 1E is debatable, as mentioned earlier), and Figure 1B has a 16th-level syncopation. 
How can we quantify the amount of syncopation in a melody? A number of solutions to this problem have been put forth. Nearly all of these proposals consider only the pattern of onsets in the melody (and the length of notes, which - if defined in terms of inter-onset interval-is implicit in the onset pattern) and its alignment with the meter, disregarding other possible sources of phenomenal accent. Following Tan, Lustig, and Temperley (2019), I will refer to such definitions of syncopation as positional. Perhaps the most influential proposal of this type is that of Longuet-Higgins and Lee (1984). These authors define a syncopation as a note on a weak beat with no note (either a rest or a continuation of the previous note) on the following stronger beat; they further define the "strength" of the syncopation as decreasing with the strength of the weak beat and increasing with the strength of the following strong beat. Huron and Ommen (2006) also define syncopation in purely positional terms; most other quantitative models of syncopation have done so as well (for a review, see Gomez, Thul, \& Toussaint, 2007).[2] The problem with such definitions, as we have already seen, is that agogic accents are not sufficient to define syncopation: even when an onset pattern may suggest syncopation, the degree of perceived syncopation can vary enormously depending on other musical features.

The six passages in Figure 2, all from 19th-century English and Scottish songs, illustrate this point in more detail. The boxed segments in the six examples are virtually identical in their pattern of note onsets, in relation to the meter. (The only difference is that some begin at the beginning of a $4 / 4$ measure, some at the midpoint, and some at the beginning of a $2 / 4$ measure; I do not consider these distinctions further here.) Figures $2 \mathrm{~A}$ and $2 \mathrm{~F}$ were presented earlier (Figures $1 \mathrm{E}$ and $1 \mathrm{~A}$ ). I have already suggested that Figure $2 \mathrm{~F}$ feels much more syncopated than Figure 2A; the question is why. Clearly, the reason is the differing levels of accentuation of the second note in the segment (hereafter just the "second note"). At least four factors contribute to this:

1. The second note in Figure 2F carries a change of syllable; the one in Figure 2A does not. This is important, though not decisive; the second note in Figure 2B carries a change of syllable, but seems only very mildly syncopated, if at all. (Patterns in which the second-position note repeats the pitch of the previous note- no example is shown here-also carry little sense of syncopation.) The vast majority of syncopations considered in this article, in all vocal repertoires, have a change of syllable on the syncopated note; I will call these syllabic (as opposed to melismatic) syncopations.

2. The second note in Figure 2F is extended to the next onset, while that in Figure $2 \mathrm{~A}$ is followed by a rest. (I will say that the second note in Figure $2 \mathrm{~F}$ is continued, while that in Figure 2A is curtailed.) Most models of meter perception would treat the patterns in Figures $2 \mathrm{~A}$ and $2 \mathrm{~F}$ as rhythmically equivalent, though Lerdahl and Jackendoff's model recognized the effect of duration.[3] Comparing Figures 2B and 2C reveals the effect of this factor; the latter seems slightly more syncopated.

3. The second note in Figure 2F moves upward; the second note in Figure 2A moves downward. This, again, is a subtle factor. In general, higher pitch does not appear to be a significant source of phenomenal accent; in analyses of musical corpora, I have found that strong-beat notes are no higher in pitch on average than weak-beat notes.[4] But in this situation, it seems intuitively to affect accentuation; to my ears, Figure 2D feels more syncopated than Figure 2C.

4. The second note in Figure $2 \mathrm{~F}$ is approached by leap; that in Figure 2A is approached by step. Again, this is not usually considered a source of phenomenal accent, but it does seem to play a role in syncopation: Figure 2E (descending by leap) carries a stronger sense of syncopation than Figure 2C (descending by step). Figure 2F, which combines ascending motion with a leap, seems more syncopated than either 2E or 2D; thus, both direction and interval size to the syncopated note play a role.

These four factors could be combined in a variety of ways, and are; Figures 2B through 2E have some of the syncopating factors but not all, creating intermediate levels of syncopation. Thus, there is a continuum between clearly syncopated melodic patterns like Figure $2 \mathrm{~F}$ and clearly unsyncopated ones like Figure 2A. The ragtime-era example presented earlier (Figure 1C) has all of the syncopating features of Figure 2F: the second note is syllabic, continued rather than curtailed, and approached by ascending leap. One additional factor is present in Figure 1C but not in Figure 2F, namely, cross-rhythm: The repeated pattern of pitch and rhythm in Figure 1C (E-G-E-G) hints at a dotted-quarter pulse. I will say more about cross-rhythm in a later section. 
A

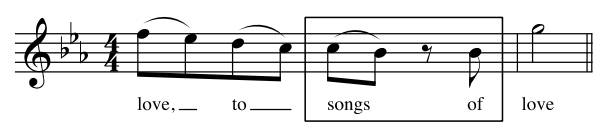

B.

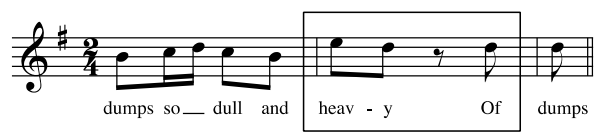

C.

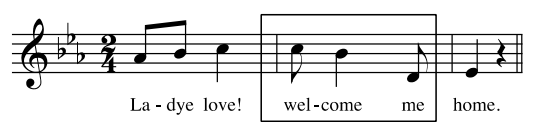

D.

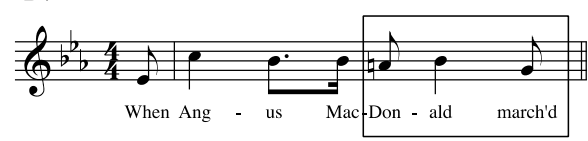

E.

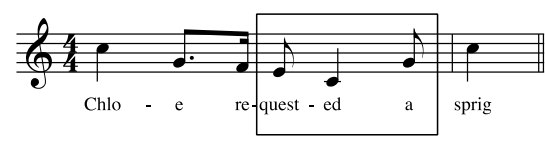

F.

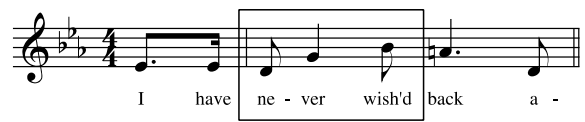

Fig. 2. (A) Thomas Morton and Henry Bishop, "Pretty Mocking Bird," mm. 28-9, in Songs of England (SOE), 63; (B) William Shakespeare and Richard Stevens, "Sigh No More, Ladies," mm. 13-14, in SOE, 232; (C) Thomas Bayly, "Gaily the Troubadour," mm. 22-4, in SOE, 23; (D) Frederic Weatherly and Joseph Roeckel, "Angus MacDonald," mm. 4-5, in Songs of Scotland (SOS), 69; (E) William Shield and John O'Keefe, "The Thorn," mm. 3-4, in SOE, 146; (F) Dora Greenwell and Jacques Blumenthal, "Answers," mm. 25-6, in SOS, 87.

\section{QUANTIFYING SECOND-POSITION SYNCOPATION IN EUROPEAN AND AMERICAN SONGS}

In this section I present a corpus analysis of second-position syncopation in European and American vocal music. I build on Temperley and Temperley's (2011) study of the Scotch snap, but go beyond it in three ways: by including 8th-level syncopations; by considering other accentual factors besides onset pattern, as discussed in the previous section; and by including American songs, allowing a comparison of British and American uses of second-position syncopation.

My corpus consists of eleven books of songs: two American, one English, two German, two French, three Italian, and one Scottish (see Table 1). One of the American books is a collection of slave songs; I refer to this as the African-American corpus. The other is a general collection of American songs. It contains one section of African-American songs, which I excluded; thus, it seems reasonable to describe it as the EuroAmerican corpus. Of the nine European books, seven are from around 1900 and contain a broad variety of songs; the remaining two are books of German Lieder and Italian arias. The African-American songbook is from 1867; the Euro-American book is from 1940, but songs are organized chronologically and only sections pertaining to pre-1900 songs were analyzed.[5] The European and Euro-American books were chosen so as to maintain a similar balance of materials across all six nations - a mixture of attributed and unattributed songs in a variety of genres (love songs, work songs, story-telling ballads, and so forth). Most of the attributed songs are of 19th-century origin, except for the Italian aria book. As for the African-American songs, all are unattributed and most are religious. 
Table 1. Sources used in the study of second-position syncopation.

\begin{tabular}{|l|l|l|l|}
\hline Corpus & Sources & $\begin{array}{l}\text { Number of } \\
\text { eligible songs }\end{array}$ & $\begin{array}{l}\text { Number of } \\
\text { eligible } \\
\text { measures }\end{array}$ \\
\hline English & $\begin{array}{l}\text { Hatton and Fanning, eds., Songs of England, } \\
\text { vol. 1 (1873) }\end{array}$ & 78 & 3362 \\
\hline French & $\begin{array}{l}\text { Songs of France (c. 1880) } \\
\text { Jameson and Heacox, eds., Chants de France } \\
\text { (1922) }\end{array}$ & 85 & 3565 \\
\hline German & $\begin{array}{l}\text { Spicker, ed., Songs of Germany (1904) } \\
\text { Easton, ed., Fifty Selected Songs by } \\
\text { Schubert, Schumann, Brahms, Wolf, and } \\
\text { Strauss (1951) }\end{array}$ & 99 & 2362 \\
\hline Italian & $\begin{array}{l}\text { Hayes, ed., Songs of Italy (c. 1880) } \\
\text { Marzo, ed., Songs of Italy (1904) } \\
\text { Baker, ed., Twenty-Four Italian Songs and } \\
\text { Arias of the 17th and 18th Centuries } \\
\text { (1948) }\end{array}$ & 57 & 2385 \\
\hline Scottish & $\begin{array}{l}\text { Songs of Scotland (1888) } \\
\text { Allen, Ware, and Garrison, eds., Slave Songs } \\
\text { of the United States (1867) }\end{array}$ & 130 & 1383 \\
\hline Euro-American-American & $\begin{array}{l}\text { Downes and Siegmeister, eds., A Treasury of } \\
\text { American Song (1940), pp. 26-167, 215-87 }\end{array}$ & 90 & 1373 \\
\hline
\end{tabular}

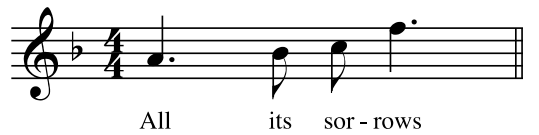

Fig. 3. G. A. Hodson, “Tell Me, Mary, How To Woo Thee,” m. 15, in Songs of England, 222.

I take these songbooks as evidence of the prevalence of certain types of syncopation in late 19thcentury cultures. They are, of course, imperfect indicators in this regard. One might question whether the choice of songs in each book constitutes a balanced representation of all the culture's vocal music (if such a thing is even possible). Not all of the attributed songs in the corpus are by natives or even residents of the associated nations, and some might be regarded as imitations of the national style rather than specimens of it.[6] In addition, in the case of songs transcribed from performance, there may be biases in the transcription process that distort the rhythms (I will return to this issue). But there is no perfect corpus for a project such as this, and these materials seem as suitable as any.

As shown in the previous section, quantifying second-position syncopation is not a straightforward matter: whether something is a syncopation is a matter of "more-or-less," not "all-or-nothing." The corpus data could have been analyzed in a number of ways; here I present just a few analyses that I hope the reader will find convincing. I analyzed all songs in simple meter-that is, $4 / 4,3 / 4,2 / 4$, or $2 / 2$. Compound meter songs $(6 / 8)$ were excluded because they do not fit neatly into the framework of second- and fourth-position syncopations assumed here; in any case, compound meter is much less common than simple meter in 20thcentury popular music, so it seems less relevant for the current study.[7] (More than half of the songs in the Italian books were excluded for this reason.) The third and fourth columns of Table 1 show the number of songs and measures remaining in each corpus after this exclusion.[8] I considered both 16th- and 8th-level syncopations; assuming a quarter-note tactus level, such syncopations are one or two levels below the tactus, respectively. In $2 / 2$, the tactus is generally assumed to be the half-note; but only a very small number of songs in the entire corpus (less than 3\%) are notated in this meter, and even in those that are, the choice of tactus sometimes seems quite debatable.[9]

I began by counting the number of syncopations in the seven corpora (English, Scottish, French, German, Italian, African-American, and Euro-American) defined in purely positional terms. Defined in this way, an 8th-level second-position syncopation is a pattern consisting of a note on a half-note beat (or a 
dotted-half-note beat in 3/4) with another note on the following 8th-note beat that is at least a quarter-note in length, with length defined as inter-onset interval. The definition of 16th-level second-position syncopations is similar: a note on a quarter-note beat with a long note (8th-note or longer) on the following 16th-note beat. I will call all such patterns "onset syncopations," though I have already said that some such patterns are not really syncopations. All of the boxed segments in Figure 2 are 8th-level onset syncopations; the definition also includes longer syncopated notes, such as the last note of Figure 3. One could simply define a second-position syncopation as a long second-position note, without requiring a note on the preceding strong beat; however, virtually every long second-position note I encountered had a note on the previous strong position, so it seemed appropriate to include it in the definition. I then counted the number of second-position syncopations featuring all of the syncopation-increasing factors discussed earlier (except cross-rhythm); I call such patterns "acute syncopations." Thus, an acute syncopation is a second-position syncopation (as defined above) in which the syncopated note is syllabic, continued, and approached by ascending leap. To be precise, "continued" means that the actual duration of the syncopated note is at least a quarter-note (for an 8th-level syncopation) or an 8th-note (for a 16th-level syncopation). Of the excerpts in Figure 2, only $\mathrm{F}$ is an acute syncopation; Figures $1 \mathrm{~B}, 1 \mathrm{C}$, and 3 are acute syncopations as well.

We first consider 16th-note syncopations. The first column of numbers in Table 2 shows the number of onset syncopations in each corpus, followed (in parentheses) by the number per measure. The per-measure numbers are more meaningful than the sheer counts, since the corpora vary in size. The second column shows the number of songs in each corpus containing at least one onset syncopation, shown also as percentages of the total.[10] For the European nations, the results resemble those found in Temperley and Temperley's (2011) Scotch snap study: 16th-level second-position onset syncopations are far more common in the English and Scottish corpora than in the three continental corpora.[11] The third and fourth columns show the same figures for acute syncopations. Acute 16th-level syncopations are non-existent in the three continental corpora, but there are a handful in the English corpus and a larger number in the Scottish corpus. The AfricanAmerican corpus has a relatively high incidence of both onset and acute syncopations, similar to the Scottish corpus in both cases; the Euro-American corpus features a similar incidence of onset syncopations to the English corpus, but hardly any acute syncopations.

Turning to 8th-note syncopations, the situation is more complex (Table 3). Once again, the first column shows the frequency of second-position onset syncopations. We now see a strong presence of onset syncopations in the continental corpora; in particular, the frequency in the Italian corpus is comparable to that in the English corpus. Inspection of the continental syncopations shows that the majority are similar to Figures 2A and 2B: appoggiatura (descending-step) patterns or pitch repetitions, usually at the end of a phrase. The fondness for such patterns in Italian vocal music is well-known (Dean, 1977; Hansell, 1968). Once we limit the count to acute syncopations, the picture changes dramatically. There are only two instances of acute syncopations in any of the continental corpora, arising in two verses of a single French song; the first is shown in Figure 4. The English and Scottish corpora contain a total of 26 instances (two of these were shown earlier in Figures 2F and 3). The English corpus now shows a higher incidence of onset syncopations than the Scottish corpus, but a lower incidence of acute syncopations. The incidence of onset syncopations is higher in the Euro-American corpus than in the British ones, and higher still in the African-American corpus; the two American corpora also have more frequent acute syncopations than the British corpora. Figures 5 and 6 summarize these results in graphic form.[12] 
Table 2. 16th-level second-position syncopations.

\begin{tabular}{|l|c|c|c|c|}
\hline & \multicolumn{2}{|l|}{ Onset Syncopations } & Acute Syncopations \\
\hline & $\begin{array}{c}\text { Occurrences } \\
\text { (per measure) }\end{array}$ & $\begin{array}{c}\text { Songs } \\
\text { containing } \\
\text { (percent) }\end{array}$ & $\begin{array}{c}\text { Occurrences } \\
\text { (per measure) }\end{array}$ & $\begin{array}{c}\text { Songs containing } \\
\text { (percent) }\end{array}$ \\
\hline English & $91(.027)$ & $20(26)$ & $13(.004)$ & $6(6)$ \\
\hline French & $2(.001)$ & $1(1)$ & $0(0)$ & $0(0)$ \\
\hline German & $10(.004)$ & $4(4)$ & $0(0)$ & $0(0)$ \\
\hline Italian & $5(.004)$ & $2(3)$ & $0(0)$ & $0(0)$ \\
\hline Scottish & $118(.085)$ & $24(33)$ & $32(.023)$ & $10(14)$ \\
\hline $\begin{array}{l}\text { African- } \\
\text { American }\end{array}$ & $109(.068)$ & $41(31)$ & $28(.017)$ & $15(11)$ \\
\hline $\begin{array}{l}\text { Euro- } \\
\text { American }\end{array}$ & $32(.023)$ & $10(11)$ & $1(.001)$ & $1(1)$ \\
\hline
\end{tabular}

Table 3. 8th-level second-position syncopations.

\begin{tabular}{|l|c|c|c|c|}
\hline & \multicolumn{2}{|l|}{ Onset Syncopations } & Acute Syncopations & \\
\hline & $\begin{array}{c}\text { Occurrences } \\
\text { (per measure) }\end{array}$ & $\begin{array}{c}\text { Songs } \\
\text { containing } \\
\text { (percent) }\end{array}$ & $\begin{array}{c}\text { Occurrences } \\
\text { (per measure) }\end{array}$ & $\begin{array}{c}\text { Songs } \\
\text { containing } \\
\text { (percent) }\end{array}$ \\
\hline English & $137(.041)$ & $29(37)$ & $14(.004)$ & $6(6)$ \\
\hline French & $21(.006)$ & $10(12)$ & $2(<.001)$ & $1(1)$ \\
\hline German & $41(.019)$ & $12(12)$ & $0(0)$ & $0(0)$ \\
\hline Italian & $90(.038)$ & $16(28)$ & $0(0)$ & $0(0)$ \\
\hline Scottish & $35(.025)$ & $10(14)$ & $12(.009)$ & $6(8)$ \\
\hline $\begin{array}{l}\text { African- } \\
\text { American }\end{array}$ & $114(.071)$ & $48(37)$ & $23(.014)$ & $15(11)$ \\
\hline $\begin{array}{l}\text { Euro- } \\
\text { American }\end{array}$ & $68(.050)$ & $24(27)$ & $19(.014)$ & $9(10)$ \\
\hline
\end{tabular}

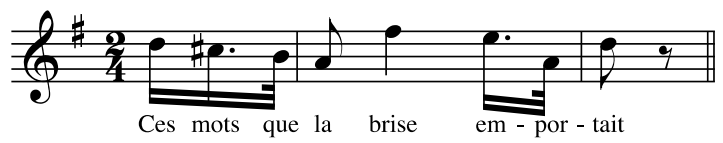

Fig. 4. Marc Constantin and Pierre-Jacques Cheret, "Le Petite Mousse Noir," mm. 11-13, in Songs of France, 188.

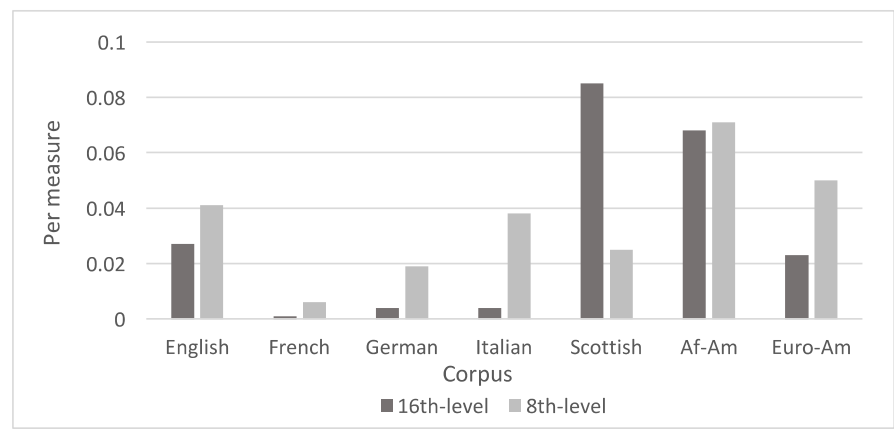

Fig. 5. Second-position onset syncopations. 


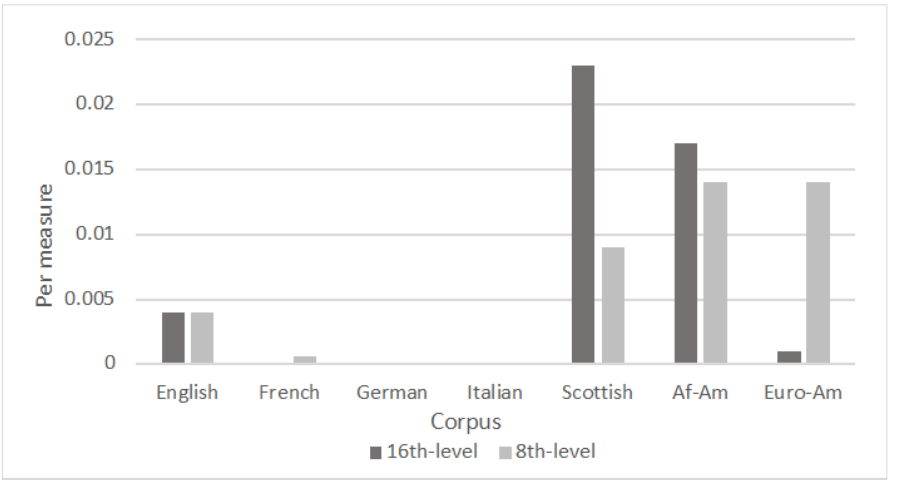

Fig. 6. Second-position acute syncopations.

A.

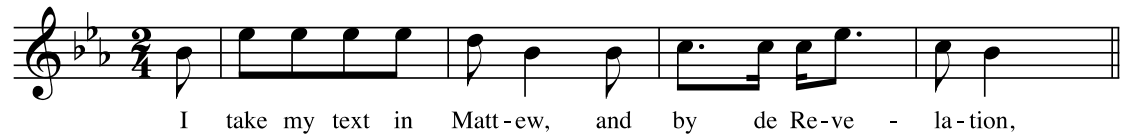

B.

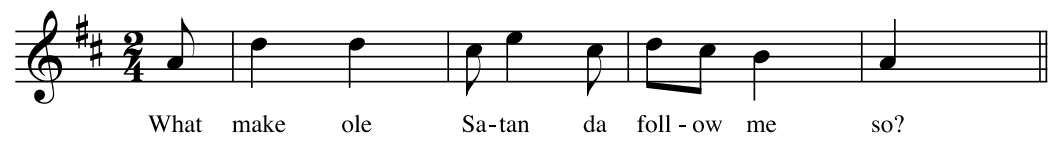

Fig. 7. (A) "There's a Meeting Here Tonight," mm. 1-4, in Slave Songs of the United States, 9; (B) "Hold the Light," mm. 1-4, in Slave Songs of the United States, 10.

The data presented here shows that second-position syncopations had a strong presence in pre-20thcentury British music, much more so than in the music of other Western European nations. This difference is somewhat apparent in the data for onset syncopations, but emerges more clearly when other sources of accentuation are considered. (As one might expect, syncopations of intermediate strength - for example, those with descending leaps and ascending steps-seem more common in British and American songs than in continental ones also, though I have not analyzed this quantitatively.) If we overlook the differences between 8th and 16th-level syncopations (which are interesting but not my main concern), collapsing the two together, it seems fair to say that acute syncopations were a stylistic option in all four of the Anglophone musical cultures: English, Scottish, Euro-American, and African-American. In some respects, secondposition syncopations are more common in American songs than in British ones: this is particularly evident with 8th-level syncopations (both onset and acute). It is possible that the use of these patterns was reinforced by African-American (or African) musical traditions.[13] But it seems likely that the prominence of secondposition syncopation in American music was at least partly the result of British influence. Qualitative inspection of the music reinforces this conclusion: In general, I see little difference between the English, Scottish, Euro-American, and African-American uses of second-position syncopation (though one significant difference will be discussed below). Most of the syncopated patterns in the Euro-American and African-American corpora would not seem out of place in an English or Scottish song. Figure 7 shows two representative phrases from Slave Songs in the United States; compare these with the English and Scottish excerpts in Figure 2. 


\section{FOURTH-POSITION SYNCOPATION AND CROSS-RHYTHM}

In the first section of this paper, I distinguished between second-position syncopations, occurring on the second quarter of a metrical unit, and fourth-position syncopations, occurring on the fourth quarter of such a unit. (An example of a fourth-position syncopation was given in Figure 1D.) Both devices are common and important in 20th-century popular music. An important difference between second- and fourth-position syncopations (in vocal music) is that the latter usually carry a stressed syllable. This can create a conflict between meter and stress: In Figure 1D, the syllable "stock-" is more stressed than the previous syllable "of," but is on a weaker beat. This conflict can be resolved by viewing the syncopation as displaced or anticipatory: The fourth-position note really "belongs" on the following strong beat, but has been shifted to the earlier weak beat (Fox, 2002; Tan, Lustig, \& Temperley, 2019). Second-position syncopations could also be regarded as anticipatory (with the note belonging on the third position), but there is less motivation for doing so; generally, the second-position syllable is less stressed than the first-position one (this is the case in all the excerpts in Figures 2, 3, and 7), so there is no conflict between stress and meter. (And if the secondposition syllable was more stressed than the first-position one, shifting it to the third position would not resolve the conflict, because it would still be metrically weaker than the first-position note.)

It is instructive to consider the incidence of fourth-position syncopations in the songbooks used in the previous corpus analysis. Regarding the European corpora (including the English and Scottish ones), there is not a single clear example of an anticipatory fourth-position syncopation in any of the five repertoires. Even defined in terms of onset pattern - an onset on the fourth quarter of a quarter-note or half-note unit (or the last 8th-note of a dotted-half-note unit in the case of 3/4), with no note on the following strong beatfourth-positions are extremely few in number. And in those instances that do occur, the syncopated note invariably carries an unstressed syllable or a melisma. Figure 8A shows one instance. The second syllable of "shoul-ders" could be described as a fourth-position onset syncopation; but since it is unstressed, it is quite different in effect from the syncopation shown in Figure 1D. Perhaps more surprisingly, fourth-position syncopations are extremely rare in the Euro-American and African-American corpora as well. The EuroAmerican corpus contains no clear-cut examples; the African-American corpus contains just one, shown in Figure 8B. This has some resemblance to 20th-century fourth-position syncopation, with a stressed syllable ("Je-") on the fourth 8th-note beat of a half-note span; but the syncopation occurs at the beginning of a phrase, which is unusual. I also examined two other late-19th-century books of African-American songs in an informal way (Fenner, 1886; Jubilee Songs, 1872), and both present the same general picture as Slave Songs of the United States: second-position syncopations are abundant, while fourth-position syncopations are virtually non-existent.

In short, none of the song corpora examined here-European, Euro-American, or AfricanAmerican - show clear evidence of the type of fourth-position syncopation typical of 20th-century popular music. When and how did this type of syncopation originate? I intend to explore this question in a future study. Very briefly, fourth-position syncopation appears to have emerged only in African-American music of the very late 19th-century-ragtime and its immediate predecessors. Berlin (1980) shows that fourthposition ("tied") syncopations exploded in popularity in ragtime after 1900, but that occasional instances occurred before the turn of the century (see also Koops, Volk, \& Bas De Haas, 2015). Some of the earliest examples are in piano accompaniments to songs; Figure 9 shows one from 1897 (I apologize for the racist character of this example). The right hand of the piano part is clearly following the vocal part; both the vocal and the piano part contain second-position syncopations, but only the piano part has fourth-position syncopations. This brings out the anticipatory character of the fourth-position syncopations: each one is understood to belong with the stressed syllable on the following beat ("moke," "broke"). Notated fourthposition syncopations became common in vocal parts a few years later. Thus, while second-position syncopations were pervasive in ragtime right from the beginning, fourth-position syncopations were only introduced gradually: first in piano parts, later in vocal parts. The situation is further complicated by the fact that fourth-position syncopations sometimes seem to have been used in performance before they were notated; again, I will address this issue further in future work.

In my earlier discussion of second-position syncopation, I mentioned yet another important rhythmic device of 20th-century popular music, namely, cross-rhythm. When a musical pattern is immediately repeated, there is a tendency to perceive a metrical level that is aligned with the pattern - a phenomenon known as parallelism (Lerdahl \& Jackendoff, 1983). Cross-rhythm occurs when a parallelism conflicts with the underlying meter; in Figure 1C, the repeated 8th-quarter pattern (in both rhythm and pitch) suggests a dotted-quarter metrical level that undermines the quarter-note pulse. The European and Euro- 
American corpora used in the current study contain no convincing examples of cross-rhythm. One might point to something like the 8th-quarter-8th-quarter pattern in Figure $2 \mathrm{C}$ ("welcome me home"); but the fact that it is not supported by a repeated pitch pattern makes it seem accidental. By contrast, the AfricanAmerican songbooks that I examined contain several clear instances of cross-rhythm. One is shown in Figure 10: notice the repeated two-note pitch motive (A-C-A-C) reinforcing the rhythmic pattern. Such examples suggest that the cross-rhythms of ragtime and later popular styles have roots in African-American music, though this deserves further exploration; Caribbean music may also have been an influence (Manuel, 2009; Washburne, 1997).

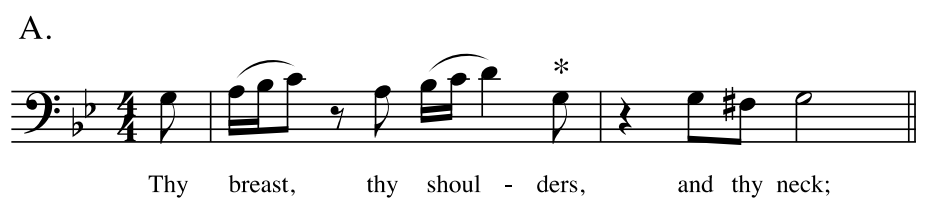

B.

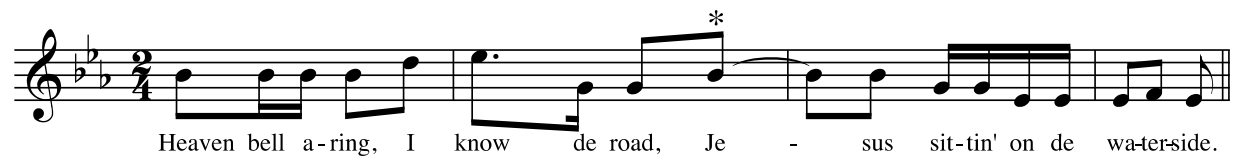

Fig. 8. (A) Henry Purcell, "Ye Twice Ten Hundred Deities," mm. 57-9, in Songs of England, 243; (B) "Jesus on the Water-Side," mm. 5-8, in Slave Songs of the United States, 28.

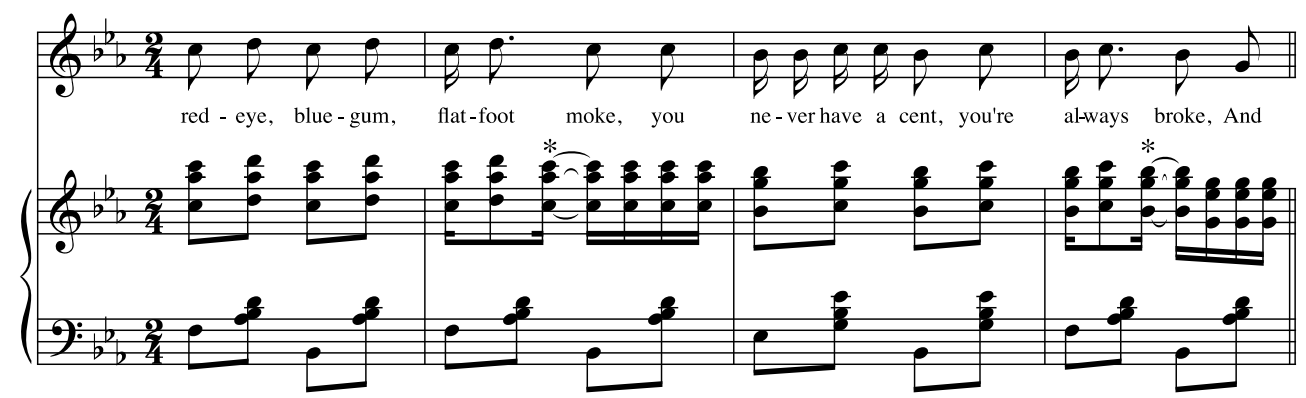

Fig. 9. Irving Jones, "Take Your Clothes and Go," mm. 25-8.

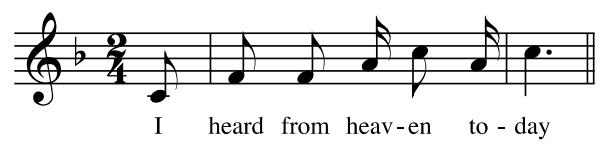

Fig. 10. "Peter, Go Ring Them Bells," mm. 16-18, in Cabin and Plantation Songs, 175.

\section{CONCLUSIONS AND FURTHER ISSUES}

The corpus data presented here shows a complex pattern of national differences in the use of second-position syncopation. For present purposes, certain features of the data are of particular interest. Comparing the use of second-position syncopation between British (English and Scottish) and continental (French, German, and Italian) songs, we find a much higher incidence in the British corpora. When only onset patterns are considered, this pattern is clearly evident at the 16th-note level, reinforcing the conclusions of Temperley and Temperley (2011). At the 8th-note level, second-position onset syncopations show a similar frequency in English, Italian, and Scottish songs; however, acute syncopations - defined not only by onset level but by text-setting, duration, and pitch contour-are almost exclusively confined to English and Scottish songs. Broadly speaking, the frequency of second-position syncopations in 19th-century British songs resembles that in Euro-American and African-American songs of the period, though 8th-level syncopations are 
somewhat more common in American songs. It seems likely, then, that this aspect of syncopation in 20thcentury popular music is at least partly due to British influence. Other important aspects of 20th-century syncopation - fourth-position syncopation and cross-rhythm - seem much more likely to be of AfricanAmerican origin.

One might wonder how the observed differences in rhythmic practice between European nations might be explained. One possibility is that they arise from differences in language. The idea that rhythmic differences between musical cultures might have linguistic roots has been explored in several recent studies, with mixed results (Lee, Brown, \& Müllensiefen, 2017; Patel \& Daniele, 2003; Temperley, 2017; VanHandel \& Song, 2010). Temperley and Temperley (2011) proposed that the greater frequency of the Scotch snap in British songs than in German and Italian ones might be due to the higher frequency of short stressed syllables in English (requiring a short note on the strong beat). In the case of Italian, I observed earlier that most of the onset syncopations in the corpus arise in appoggiatura (or repeated-note) patterns at phrase endings. It has been suggested that this preference is due to the tendency of Italian words and phrases to have stress on the penultimate syllable (Dean, 1977, p. 392; Hansell, 1968, pp. 236-7). In French, by contrast, the stress of a phrase is normally on the final syllable, though syllabification of the usually-silent final "e" creates strongweak phrase endings in some cases (as in the first line of "La Marseillaise": "All-ons en-fants de la Pa-trie").

The current study raises several theoretical and methodological issues. One concerns the distinction between 8th- and 16th-level syncopations. I have already noted that this distinction relies on notational decisions that may be somewhat subjective. At a deeper level, one might wonder how distinct the two types of syncopation are in cognitive terms. In general, nations that have a high incidence of 8th-level syncopations (onset or acute) tend to have a high incidence of 16th-level syncopations as well (see Figures 5 and 6); the most striking exceptions are the much higher incidence of onset syncopations at the 8th level than at the 16th level in Italian songs, and the higher incidence of acute syncopations at the 8th level in Euro-American songs. Possibly, the stylistic appropriateness of syncopation at a given level depends more on the absolute tempo of that level (beats per minute) than on its relationship to the tactus (or perhaps the tactus itself is ambiguous in some cases). Another issue concerns the musical factors affecting second-position syncopation. I noted earlier that several of these factors - ascending versus descending interval, leap versus step, continued versus curtailed notes - are not generally regarded as sources of phenomenal accent, and some may question them. But even if these features do not contribute to accentuation, it seems clear that there is a difference in their use between English-speaking and continental musical styles, and a similarity across English-speaking ones; that is the crucial point for my argument. In any event, the important methodological conclusion of this study is that national differences in the use of syncopation cannot be adequately characterized by onset pattern alone; other musical features must also be considered.

\section{ACKNOWLEDGMENTS}

This article was copyedited by Scott Bannister and layout edited by Diana Kayser.

\section{NOTES}

[1] Correspondence can be addressed to: David Temperley, Eastman School of Music, 26 Gibbs St., Rochester, NY 14618, dtemperley@esm.rochester.edu.

[2] I should emphasize that the authors mentioned here-Longuet-Higgins and Lee (1984) and Huron and Ommen (2006) - acknowledge that other factors besides metric position may affect syncopation (see also Huron, 2006); thus, their "positional" definitions of syncopation are only operational ones. My point, then, is that in measuring the relative prevalence of syncopation in different musical styles or repertoires, different operational definitions may yield different results. It should be noted also that several recent models of syncopation consider syllabic stress as a factor: see Waller (2016); Condit-Schultz (2017); Tan, Lustig, \& Temperley (2019).

[3] See Lerdahl \& Jackendoff (1983), 79-80; see also Leong (2011). In a survey of meter-finding models, Gouyon \& Dixon (2005) suggest that inter-onset intervals "can be considered roughly equivalent to 
durations," and list a number of models that do so. Even Berlin seems to assume this, despite his "tied/untied" terminology $(1980,84)$.

[4] In a sample of 1585 melodies in 4/4 from the Essen corpus of European folksongs (Schaffrath, 1995), the difference in average pitch height between notes at strong and weak eighth-note positions was less than 1/10 of a semitone; a sample of 2498 classical instrumental melodies from Barlow \& Morgenstern's Dictionary of Musical Themes (1948) obtained the same result. Huron \& Royal (1996) also cast doubt on the idea that pitch contour plays a major role in accentuation.

[5] It would have been preferable to use an earlier songbook for the Euro-American corpus. However, all those that I could find contained a substantial number of English songs - both songs by English composers and English folk songs, including some contained in the English songbook used here. A Treasury of American Song also has some English songs, but seems (judging by the book's commentary) more focused on including songs and musical practices that are distinctively American.

[6] For example, Figure 1A, from Songs of Scotland, is by a German-born composer who settled in England (Corder, n.d.).

[7] 3/4 is rare in twentieth-century popular music as well, but it was included because it provides additional data and fits the current framework fairly well: the definition of 8th-note syncopations requires a slight adjustment (as explained below), while that of 16th-level syncopations requires none. A very small number of songs were in unusual meters such as $5 / 4,4 / 8$, and $4 / 2$; these were excluded. In the rare cases where only some sections of a song were in eligible meters, just those sections were included in the corpus.

[8] In counting measures, I ignored any measures of rest in the vocal line. I also skipped any partial ("pickup") measure at the beginning of a song (or a measure that followed a measure of rest and contained only a pick-up), but counted partial measures at the end of a song or preceding a measure of rest.

[9] There are a few songs in the corpus in which a half-note tactus seems appropriate. Some of these contain quarter-note patterns (such as quarter-half-quarter) that seem similar in character to 8th-level syncopations such as those in Figure 2. In a few other cases, an 8th-note tactus seems plausible (though only one song is notated in 4/8). In notating music (whether in transcription or composition), decisions must be made about how to map the metrical levels of a performed or imagined piece on to rhythmic values (for example, deciding which level should be notated as the quarter-note level) and also in deciding which level is the tactus (for example, deciding between $4 / 4$ and $2 / 2$ time signatures), and there is some subjectivity in these decisions. This is a methodological limitation of the current study that should be borne in mind.

[10] The purpose of the second and fourth columns is to check for the possibility that a high count of syncopations in a corpus was due to just one or a few songs. This does not appear to be a problem with the current data; in cases where the number of syncopations is high, they are fairly widely distributed.

[11] I used the same English songbook as that used in Temperley \& Temperley (2011); the other songbooks are different.

[12] I have not provided significance tests for these comparisons, since it does not seem helpful to do so. Regarding the questions posed in the first section of the paper, the significance of certain results seems obvious from Figures 5 and 6: the greater frequency of 16th-level onset syncopations in the British songs (combining English and Scottish songs) than in the continental songs (combining French, German, and Italian songs), and the greater frequency of acute syncopations (both 8th-level and 16th-level) in British songs than in continental songs. Regarding the American songs, my only prediction was that they would be similar to the British ones in their use of second-position syncopation, and this cannot be confirmed or disconfirmed with statistical tests. Many other differences between corpora could be examined for significance, but such tests would all be of a post hoc character, and thus of dubious value.

[13] Several authors have pointed to possible connections between African and African-American music: See Hamm (1983); Floyd \& Reisser (1984); Gridley \& Rave (1984); Southern (1997). 


\section{REFERENCES}

Allen, W., Ware, C., \& Garrison, L. (eds). (1867). Slave songs of the United States. New York: A. Simpson.

Baker, T. (ed). (1948). Twenty-four Italian songs and arias of the 17th and 18th centuries. New York: Schirmer.

Barlow, H., \& Morgenstern, S. (1948). A dictionary of musical themes. New York: Crown Publishers.

Berlin, E. (1980). Ragtime: A musical and cultural history. Berkeley: University of California Press.

Cohan, G. M. (1906). You're a grand old flag. New York: F. A. Mills.

Condit-Shultz, N. (2017). MCFlow: A digital corpus of rap transcriptions. Empirical Musicology Review, 11(2). https://doi.org/10.18061/emr.v11i2.4961

Corder, F. (n.d.) Jacques Blumenthal. Oxford dictionary of national biography. http://www.oxforddnb.com/ (accessed March 7, 2019).

Dean, W. (1977). The performance of recitative in late Baroque opera. Music \& Letters, 58, 389-402. https://doi.org/10.1093/ml/58.4.389

Downes, O., \& Siegmeister, E. (eds). (1940). A treasury of American song. New York: Howell, Soskin \& Co.

Easton, F. (ed). (1951). Fifty selected songs by Schubert, Schumann, Brahms, Wolf, and Strauss. New York: Schirmer.

Fenner, T. (ed). (1886) Cabin and plantation songs as sung by the Hampton students. New York: G.P. Putnam's \& Sons.

Floyd, S., \& Reisser, M. (1984). The sources and resources of classic ragtime music. Black Music Research Journal, 22-59. https://doi.org/10.2307/779473

Fox, D. (2002). The rhythm bible. New York: Alfred.

Gomez, F., Thul, E., \& Toussaint, G. (2007). An experimental comparison of formal measures of rhythmic syncopation. In Proceedings of the International Computer Music Conference (pp. 101-104).

Gouyon, F., \& Dixon, S. (2005). A review of automatic rhythm description systems. Computer Music Journal, 29(1), 34-54. https://doi.org/10.1162/comj.2005.29.1.34

Gridley, M., \& Rave, R. (1984). Towards identification of African traits in early jazz. The Black Perspective in Music, 12, 45-56. https://doi.org/10.2307/1214968

Hamm, C. (1983). Music in the new world. New York: Norton.

Hansell, S. (1968). The cadence in 18th-century recitative. The Musical Quarterly, 54, $228-48$. https://doi.org/10.1093/mq/LIV.2.228

Hatton, J., \& Fanning, E. eds. (1873). Songs of England, vol. 1. London: Boosey.

Hayes, M. (ed). (c. 1880). Songs of Italy. New York: Boosey.

Huron, D. (2006). Sweet Anticipation. Cambridge, MA: MIT Press. https://doi.org/10.7551/mitpress/6575.001.0001 
Huron, D., \& Royal, M. (1996). What is melodic accent? Converging evidence from musical practice. Music Perception, 13, 489-516. https://doi.org/10.2307/40285700

Jameson, R., \& Heacox, A. (eds). Chants de France. (1922). Boston: D.C. Heath.

Jones, I. (1897). Take your clothes and go. New York: Jos. W. Stern \& Co.

Jubilee songs: As sung by the singers of Fisk University (1872). New York: Biglow \& Main.

Krehbiel, H. (1914). Afro-American folksongs. New York: Schirmer.

Lee, C., Brown, L., \& Müllensiefen, D. (2017). The musical impact of multicultural London English (MLE) speech rhythm. Music Perception, 34, 452-81. https://doi.org/10.1525/mp.2017.34.4.452

Leong, D. (2011). Generalizing syncopation: Contour, duration, and weight. Theory and Practice, 36, 11150 .

Lerdahl, F., \& Jackendoff, R. (1983). A generative theory of tonal music. Cambridge, MA: MIT Press.

Longuet-Higgins, C., \& Lee, C. (1984). The rhythmic interpretation of monophonic music. Music Perception, 1, 424-41. https://doi.org/10.2307/40285271

Manuel, P. (2009). Creolizing contradance in the Caribbean. Philadelphia: Temple University Press.

Marzo, E. (ed). (1904). Songs of Italy. New York: Schirmer.

Patel, A., \& Daniele, J. (2003). An empirical comparison of rhythm in language and music. Cognition, 87, B35-B45. https://doi.org/10.1016/S0010-0277(02)00187-7

Porter, C. (1934). Anything goes. New York: Warner Brothers.

Schaffrath, H. (1995). The Essen Folksong Collection. Ed. by D. Huron. Stanford, CA: Center for ComputerAssisted Research in the Humanities.

Songs of France (c. 1880). London: Kenny.

Songs of Scotland (1888). Boston: White-Smith.

Southern, E. (1997). The music of black Americans. New York: Norton.

Spicker, H. (ed.). (1904). Songs of Germany. New York: Schirmer, 1904.

Temperley, D. (2017). Rhythmic variability in European vocal music. Music Perception, 35, 193-9. https://doi.org/10.1525/mp.2017.35.2.193

Temperley, N., \& Temperley, D. (2011). Music-language correlations and the 'Scotch snap'. Music Perception, 29, 51-63. https://doi.org/10.1525/mp.2011.29.1.51

van der Merwe, P. (1989). The origins of the popular style: The antecedents of twentieth-century popular music. New York: Oxford University Press.

VanHandel, L., \& Song, T. (2010). The role of meter in compositional style in 19th century French and German art song. Journal of New Music Research, 39, 1-11. https://doi.org/10.1080/09298211003642498

Waller, A. (2016). Rhythm and flow in hip-hop music. Unpublished doctoral dissertation, University of Rochester, USA. 
Washburne, C. (1997). The clave of jazz: A Caribbean contribution to the rhythmic foundation of an AfricanAmerican music. Black Music Research Journal, 17, 59-80. https://doi.org/10.2307/779360 